\title{
Musik Hip-Hop sebagai Bentuk Hybrid Culture dalam Tinjauan Estetika
}

\author{
Kardi Laksono', Silvia Anggreni Purba, dan Prima Dona Hapsari
}

Fakultas Seni Pertunjukan, Institut Seni Indonesia Yogyakarta

\begin{abstract}
ABSTRAK
Berbicara mengenai seni mempunyai tendensi berbicara mengenai kehidupan itu sendiri. Dalam kehidupan ini maka proses penciptaan tidak akan pernah stagnan. Dinamisasi dalam kehidupan ini akan menjadikan seni senantiasa untuk mengupayakan dirinya selalu kreatif dalam menciptakan suatu karya seni. Seni yang terlibat dalam kehidupan akan dihasilkan oleh suatu masyarakat yang mampu menangkap esensi seni dalam kehidupan itu sendiri. Seni pada akhirnya merupakan produk masyarakat sebab bagaimanapun juga seni tidak dapat melepaskan dirinya dari suatu masyarakat. Produksi seni yang bersifat kolektif, atau dirasa dan dicipta oleh masyarakat, akan mengutamakan nilai-nilai yang menubuh, mengedepankan etnisitas lokal, dan penuh dengan intepretasi.

Proses penciptaan seni dalam kehidupan manusia tidak dapat dilepaskan pada proses penciptaan kemurniaan dan hibriditas yang merupakan unsur yang mendasar. Proses penciptaan ini secara aktif terlibat dalam akulturasi atau asimilasi kebudayaan. Dilematis menjadi persoalan utama dalam terjadinya proses penciptaan tersebut, "Kemurnian" dan "hibriditas" menjadi gesekan persoalan. Hibriditas, merupakan telaah yang pas dalam melihat pembauran tersebut. Proses hibriditas menjadi semakin menarik terlebih seni yang tercipta dibentuk di masyarakat urban. Seni yang dicipta masyarakat urban menuju pada seni popular, tetapi tidak menutup kemungkinan itu semua berangkat dari masyarakat rural. Habitus, penubuhan, intepretasi individu yang tergabung dalam masyarakat menjadi proses pembentukan yang menarik.

Padatataran ini, estetika hybrid culture menjadi studi mendalam dalam melihat persoalan kemajemukan nilai-nilai pada proses pembentukan seni itu sendiri. Pengarahan penelitian ini akan ditujukan kepada pemahaman atas pembentukan estetika seni pertunjukan, dan melihat korelasi yang terjadi antara nilai-nilai hibriditas pada estetika seni pertunjukan. Hip hop merupakan jenis musik yang mengalami percampuran, pembauran, dan intepretasi ulang atas sebuah kebudayaan. Hibriditas hip hop menjadi hakiki, terlebih bila melihat esksistensi dan konsistensinya kini.
\end{abstract}

Kata kunci: Musik Hip-Hop, hybrid culture, estetika

\begin{abstract}
Hip-Hop Music as a Form of Hybrid Culture in the Aesthetics Reviews. Talking about art, it has a tendency to talk about life itself. The process of creation will never be stagnant in life. The dynamism in life will make art as an effort of seeking itself to be actively creative in creating a work of art. The art involving in life will be produced by a society that is able to capture the essence of art in life itself. Art is then ultimately a product of society because art cannot keep itself away from the society. The collective art production, or perceived and created by the community, will give more priority to the increasing values, prioritize the local ethnicity, and be full of interpretation.

The process of creating art in human life cannot be released from the process of creating purity and hybridity which are parts of a fundamental element. The process of creation is actively involved in the acculturation or assimilation of culture. Dilemma becomes the main issue in the process of creation, "purity" and "hybridity" then are the friction of problems. Hybridity, is a suitable study in reviewing such assimilation. The process of hybridity becomes increasingly attractive especially when the created art is formed in the urban society. Art that is created by the urban society leads to the popular art, but it does not rule out the possibility that all arts may derive from the rural community. Habitus, embodiment, and the individual interpretation that belong to the society become theinteresting process of formation.
\end{abstract}

Alamat korespondensi: Fakultas Seni Pertunjukan, ISI Yogyakarta, Jln. Parangtritis Km. 6,5 Sewon, Yogyakarta. E-mail: drkardilaksono@gmail.com; Hp: 085747957139 
From this point, this aesthetics of hybrid culture becomes the depth study in looking at the issues of plurality values in the formation process of the art itself. This research aims at understanding on the formation of aesthetics of performing arts, and reviewing the correlation between the values of hybridity on the aesthetics of performing arts. Hip hop is a type of music that experiences in mixing, blending, and reinterpreting on a culture. The hybridity of hip hop becomes essential, especially when we take a look at its existence and consistency today.

Keywords: Hip-Hop music, hybrid culture, aesthetic

\section{Pendahuluan}

Hauser (1982:94) menekankan bahwasanya "seni adalah produk masyarakat". Produk dari masyarakat dalam artian yang lebih mendalam mengindikasikan bahwa seni terbentuk berdasarkan proses penciptaan. Pada proses penciptaan kemurnian dan hibriditas menjadi hal yang mendasar, terlibat akulturasi atau asimilasi kebudayaan. Kayam (1981:90-93) mengatakan bahwa terjadi komunikasi seni antara pencipta dan pendukung amat didasari oleh rasa keakraban, yang berarti kemampuan kedua belah pihak untuk saling menangkap dan memberi makna dari penciptaan seni. Seni yang muncul dari dalam masyarakatnya adalah seni yang mendapat dukungan, yang akrab dengan lingkungan. Hal ini menekankan bahwa sebuah kesenian merupakan sebuah sistem yang didalamnya terbentang unsur-unsur yang saling berhubungan. Setiap unsur saling menopang dan berpadu menjadi sebuah hal yang baru.

Produksi seni yang bersifat kolektif, atau dirasa dan dicipta oleh masyarakat, akan mengutamakan nilai-nilai yang menubuh, mengedepankan etnisitas lokal, dan penuh dengan intepretasi. Dilematis menjadi persoalan utama dalam terjadinya proses tersebut, "kemurnian" dan "hibriditas" menjadi gesekan persoalan. Beberapa dari praktisi mengatakan bahwasanya seni adalah murni, tetapi beberapa dari akademisi mengatakan bahwasanya seni bersifat hybrid dalam tataran sekecil apapun, terlebih ketika masyarakat berinteraksi. Sumardjan (1980:21) menekankan bahwa kesenian akan ikut selalu berubah dan berkembang bila kebudayaannya juga selalu bersikap terbuka terhadap perubahan dan inovasi. Kebudayaan dalam keberlangsungannya tidaklah bersifat statis, budaya selalu bersifat dinamis. Selalu terjadi perubahan dan menciptakan keberlangsungan, dan disesuaikan dengan kondisi yang terjadi dalam pembentukannya.

Telaah Bourdieu -dalam pemahaman Jenkinsmenekankan bahwa habitus dan modal mempunyai nilai penting dalam arena (2013:124). Arena -menurut Bourdieu- dalam hal ini dikaitkan dengan pembentukan seni oleh masyarakat. Arena tidak terlepas dari arena itu sendiri, arena bernaung pada arena-arena dalam scope yang lebih besar. Tataran seni kolektif merupakan pembauran antarhabitus individu dalam arena tertentu, dikaitkan dengan arena pembentukan seni. Habitus individu membentuk habitus kolektif, dan kolektivitas merupakan arena dalam mempertemukan banyak habitus, bahkan membentuk habitus baru.

Dalam arena kolektif akan ditemui arena yang lebih besar ketika bertemu dengan arena kolektif lain. Arena akan terus-menerus terbentuk, dan habitus terus-menerus berbaur dan mencipta habitus baru dalam pembentukan seni. Sudut pandang Bourdieu, bahwasannya pembauran habitus pada arena membentuk pertemuan habitus yang dapat menghasilkan percampuran baru. Hibriditas, merupakan telaah yang pas dalam melihat pembauran tersebut. Proses hibriditas menjadi semakin menarik terlebih seni yang tercipta dibentuk di masyarakat urban. Seni yang dicipta masyarakat urban menuju pada seni popular, tetapi tidak menutup kemungkinan itu semua berangkat dari masyarakat rural. Habitus, penubuhan, intepretasi individu yang tergabung dalam masyarakat menjadi proses pembentukan yang menarik.

Pada tataran ini, estetika hybrid culture menjadi studi mendalam dalam melihat persoalan kemajemukan nilai-nilai pada proses pembentukan seni itu sendiri. Pengarahan penelitian ini akan ditujukan kepada pemahaman atas pembentukan 
estetika seni pertunjukan, dan melihat korelasi yang terjadi antara nilai-nilai hibriditas pada estetika seni pertunjukan. Hip hop merupakan jenis musik yang mengalami percampuran, pembauran, dan intepretasi ulang atas sebuah kebudayaan. Hibriditas hip hop menjadi hakiki, terlebih bila melihat esksistensi dan konsistensinya kini. Poin yang menarik disini adalah ketika hibriditas terjadi pada hip hop, perkembangannya begitu masif sehingga membuat pembaruan pada hip hop itu sendiri. Majemuk dan masifnya perkembangan hip hop, membuat jenis musik ini menjadi menarik. Penelitian ini akan memadupadankan konsep habitus dan hibriditas dalam menjelaskan hip hop dalam tataran masyarakat postkolonial terutama melalui konsep pemikiran Artaud mengenai Theatre of Cruelty.

Musik hip hop menjadi sedemikian menarik dengan kemajemukannya, terlebih eksistensinya yang terus terekspos dan menjadi konsumsi publik masyarakat Indonesia beberapa tahun belakangan ini. Dalam menguak permasalahan yang ada, penelitian dilakukan dengan menggunakan metode penelitian etnografi, metode penelitian sejarah, dan metode penelitian seni dalam mengintepretasikan proses hibriditas hip hop. Spreadley (2007:xxi) berpendapat bahwa etnografi merupakan metode yang menemukan dan menggambarkan organisasi pikiran dari manusia yang di dalamnya terdapat kebudayaan. Lebih mudahnya, pembacaan lebih mendalam atas permasalahan dapat dilakukan dengan metode ini. Teknik pengumpulan data kualitatif menjadi pilihan yang tepat dalam mengumpulkan data. Pembacaan sejarah atas kejadian-kejadian yang terjadi juga merupakan data yang valid dalam melihat keberadaan dangdut. Pembacaan seni yang dikhususkan pada korelasi notasi dianggap bisa menjawab secara eksplisit atas seni tersebut. Hasil temuan akan menjadi refleksi dalam melihat hibriditas urban masyarakat postkolonial dalam melihat seni pertunjukan sebagai sebuah manifesto kebudayaan.

\section{Habitus dalam Hibriditas}

Habitus dan hibriditas, memang merupakan dua konsep yang tidak menyatu, oleh karena itu memadu-padankan habitus dan hibriditas menjadi hal yang menarik, mengingat masing-masing konsep berdiri sendiri dan telah menjadi teori. Pada dasarnya hibriditas menurut Bhaba (2007:124-126) adalah sebuah proses penciptaan identitas kultural menjadi jelas. Hibriditas lebih mengarah kepada perubahan identitas yang berujung pada perubahan subjektif. Maksud Bhaba dalam ranah ini adalah penggambaran atas bergabungnya dua bentuk budaya yang memunculkan sifat-sifattertentu dari tiap bentuknya, dan menjadi sifat yang dimiliki keduanya. Young (1995:9) menekankan bahwa:

The use of the term 'bybridity' to describe the offspring of humans of different races implied, by contrast, that the different races were different species: if the hybrid issue was successful through several generations, then it was taken to prove that humans were all one species, with the different races merely subgroups or varieties—which meant that technically it was no longer hybridity at all.

Pernyataan Young secara eksplisit menggambarkan adanya perbedaan ras yang menyatu dengan proses. Perpaduan antara satu unsur dengan unsur lain menjadi kunci dalam penerapan hibriditas.

Tidak terlepas pada hibriditas, adapun langkah-langkah yang diterpakan dalam proses penerapan perpaduan (baca:hibriditas) tersebut. Mimikri menjadi proses dalam penerapan hibriditas. Bhabha (2007:126) menyatakan bahwa mimikri adalah proses peniruan yang terjadi antara dua identitas berbeda dan juga tanda dari yang tidak teraproproasi, dan mimikri merupakan suatu tindakan yang sengaja atau tanpa sadar dilakukan pada interaksi atau hubungan sosial dalam pertahankan dominasi. Adanya proses imitasi yang terjadi pada percampurannya. Mimikri teraplikasikan dengan dua cara, yakni: tanpa sadar dan disengaja. Dalam artian lebih luas, bahwa mimikri dapat terjadi dengan secara tidak sengaja ketika 'penubuhan' atas sebuah budaya sudah terjadi. Proses imitasi akan berbaur dengan adanya intepretasi, terlebih ketika akan dipadu-padankan dengan kebudayaan lainnya.

Hibriditas yang diwujudkan dengan proses mimikri dipertajam dengan konsep habitus milik Pierre Bourdieu. Habitus menurut Bourdieu (1990:53) merupakan hasil ketrampilan yang 
menjadi tindakan praktis yang tidak harus selalu disadari, yang kemudian menjadi sumber penggerak dalam lingkungan sosial tertentu. Keterampilan tersebut terjadi tidak semata-mata begitu saja, tetapi terjadi pengulangan secara terus menerus. Menurut Bourdieu (1977:78):

The habitus, the durably installed generative principle of regulated improvisations, produces practices which tend to reproduce the regularities immanent in the objective conditions of the production of their generative principle.

Bourdieu menekankan bahwa habitus merupakan sebuah keteraturan terbentuk karena adanya pembiasaan yang berulang. Pembiasaan yang berulang terjadi karena adanya latihan yang terus menerus hingga membentuk keteraturan yang bersifat immanent. Habitus merupakan struktur yang menstruktur seorang individu dalam disposisi sehingga menubuh di luar kesadaran si individu. Pada dasarnya Habitus merupakan kebiasaan yang ada pada tubuh, sehingga semuanya seperti bersifat otomatis atau bekerja diluar kesadaran. Habitus terjadi jika terkonstruk di kepala individu, terbiasa dengan praktik dan lingkungan, dan toksonomi praktis (Jenkins, 1990:4).

Terkait dengan hal tersebut, Richter (2012:85) juga menyatakan bahwa:

Habitus is therefore a way to explain how people's senses of reality and perceptions of life chances are conditioned by mental structures they have developed through experience. By shifting the emphasis somewhat, I want to suggest that a person's involvement in a variety of experiences can broaden their scope of imaginable and realizable positions. In this light, the idea of habitus 'plasticity' helps to focus attention on the fact that deeply embedded, habitual behaviour, or what Bourdieu (1977:78) calls 'history turned into nature, is at the same time influenced by the physical and mental agility for 'playing the game' that interaction in differing social settings enables.

Hal ini mengidikasikan bahwa dalam individu sudah terbentuk struktur mental yang dikembangkan melalui pengalaman-pengalaman dan membentuk pengalaman kolektif. Pengalaman tersebut juga membentuk manifestasi perilaku dan pengetahuan baru yang memperkuat struktur di kepala mereka yang terkadang membuat sebuah hal makin tidak disadari. Terjadi pembiasaan dengan intepretasi dan kreatifitas atas sebuah kondisional konteks yang berubah-ubah tetapi dalam satu lingkup yang sama.

Dari hal tersebut pembiasaan terjadi karena adanya latihan yang berulang, latihan yang berulang dapat tercipta berdasarkan apa yang menjadi habitus itu sendiri, seperti halnya budaya, keluarga, lingkungan, sekolah, dan banyak lagi. Terkait dengan hal tersebut Bourdieu (1994:1) menjelaskan bahwa:
culture as a gift of nature, scientific observation shows that cultural needs are the product of upbringing and education: surveys establish that all cultural practices (museum visits, concert- going, reading etc.), and preferences in literature, painting or music, are closely linked to educational level (measured by qualifications or length of schooling) and secondarily to social origin.

Dari hal tersebut menjelaskan bahwa seluruh praktik kultural seperti halnya musik sangat berkaitan dengan tingkat pendidikan dan lingkungan sosial. Tingkat praktik kultural membuat peluang-peluang dalam mengkonstruksi masyarakat dibawah sadar mereka. Bourdieu mempercayai bahwa asal usul sosial memiliki pengaruh yang sangat besar terhadap pengetahuan seseorang.

Pada dasarnya Habitus merupakan kebiasaan yang ada pada tubuh, sehingga semuanya seperti bersifat otomatis atau bekerja diluar kesadaran. Habitus-habitus yang terbentuk menjadi kekayaan modal yang teraplikasikan oleh praktik. Modal terjadi ketika kebiasaan tumbuh, menjadi investasi dalam penubuhan. Dalam penelitiannya tentang praktik, Bourdieu berpendapat bahwa seluruh kehidupan sosial pada dasarnya bersifat praktik, karena berada dalam ruang dan waktu, serta tidak secara sadar diatur dan digerakan. Bourdieu (dalam Jenkins, 1992:42):

the practical mastery of the logic or of the
imminent necessity of a game-a mastery acquired
by experience of the game, and one which works
outside conscious control and discourse (in the
way that, for instance, techniques of the body do Praktik tidak terjadi pada ruang yang kosong, Praktik berkerja pada field. Praktik merupakan sebagai gabungan dari habitus dan modal yang 
dibuktikan di field. Jenkins (1992:52) menyatakan bahwa habitus, modal dan praktik teraplikasikan pada arena atau field. Field merupakan suatu arena sosial yang di dalamnya ada perjuangan atau maneuver untuk memperebutkan sumber atau akses yang terbatas. Praktik berada dalam field, yang merupakan hasil dari capital yang terjadi karena habitus. Ketika seseorang dengan praktiknya melawan orang lain disebut sebagai field of struggle, dan perjuangan untuk mencapai eksistensi. Habitus, modal dan praktik dalam arena mengkonstruksi segala sesuatu menjadi satu keterkaitan.

Bourdieu menjelaskan bahwa seluruh praktik kultural seperti halnya lukisan atau musik sangat berkaitan dengan tingkat pendidikan dan lingkungan sosial. Tingkat praktik kultural membuat peluang-peluang dalam mengkonstruksi masyarakat dibawah sadar mereka. Bourdieu mempercayai bahwa asal usul sosial memiliki pengaruh yang sangat besar terhadap pengetahuan seseorang. Pada hal ini budaya-budaya yang menghibrid mempunyai habitus tersendiri. Hibriditas pada habitus terjadi pada arena-arena yang ada dan mengkonstruksi sebuah hal yang baru. Penerapan habitus dan hibriditas pada hip hop, dapat diterapkan dari awal munculnya musik Dangdut itu sendiri.

\section{Hip Hop Sang Hybrid}

Hip hop merupakan jenis musik yang eksistensi dan konsistensinya terus terjaga, bahkan hip hop terus berkembang dalam ranah musikalitas. Hip hop tidak seperti jenis musik lainnya, yang terkadang menjaga nilai keasilannya. Hip hop terus berpadu-padan dengan jenis music lainnya. Pembauran hip hop dengan jenis musik dan budaya lain menjadikan hip hop semakin variatif. Pembauran itu menjadi kekhasan tersendiri pada hip hop itu sendiri. Hal ini sudah terjadi sejak hip hop itu berdiri, tidak terlepas dari kondisional yang ada dalam terbentuknya hip hop. Hip hop dalam perkembangannya mengalami rentetan proses yang panjang.

Perjalanan hip hop dari awal keberadaannya hingga hip hop pada masa sekarang ini membuktikan bahwa hibriditas menjadi landasan dari eksistensi musik hip hop. Pada dasarnya Burke (2009:51) menyatakan bahwa: All cultures are involved in one another, none is single, and pure, all are hybrid, heterogeneous. Adanya percampuran sebagai dasar dari pondasi jenis musik ini sebagai satu kesatuan. Berangkat dari hal tersebut, dapat diyakini bahwa hibriditas merupakan percampuran yang berintegrasi, dalam konsepsi ini bahkan tidak hanya integrasi tetapi berakulturasi. Terbentuk konstruksi baru yang merupakan hasil akulturasi beberapa percampuran. Pada hal ini, sesuatu konsep terapan yang baru membentuk identitas baru pada keberlangsungannya, dan dalam hal ini adalah hip hop sebagai musik hibrid. Pemikiran ini semakin terlihat dalam seni pertunjukan yang berlandaskan konsep teatrikal Artaud.

\section{Jogja Hip Hop Foundation}

Jogja Hip Hop Foundation yang sering disingkat dengan JHF merupakan salah satu group hip hop asal Yogyakarta. JHF beranggotakan Ki Ageng Gantas, Rajapati, Balance serta dikomandani oleh Marzuki 'Kill DJ.' Group hip hop ini sangat unik serta mempunyai kekhasan tersendiri sehingga group hip hop JHF ini sangat menarik untuk diteliti. JHF merupakan group hip hop yang terlahir di Yogyakarta serta tidak ada hubungan secara langsung dengan Amerika; suatu negara yang mekahirkan musik beraliran hip hop.

Sejarah lahirnya musik hip hop merupakan sejarah lahirnya kekritisan pikiran mengenai suatu keadaan sosial yang terjadi di suatu negara ataupun wilayah tertentu. Sebagaimana di Amerika maka Jogja Hip Hop Foundation pun lahir dari semangat yang sama. JHF terlahir dengan semangat kekritisan pemikiran atas kondisi sosial yang terjadi di Indonesia maupun di Yogyakarta itu sendiri. Kekritisan pemikiran dalam personil JHF ini dipadukan dengan semnagat jaman yang mencoba untuk mengkombinasikan antara keadaan modern dengan tradisi. Memang kondisi antara baik modernitas maupun tradisionalitas tidak bisa dilepaskan begitu saja di Indonesia.

Indonesia merupakan suatu negara yang tidak mengalami sejarah panjang pemikiran 
modern, namun merupakan suatu negara yang terdampak langsung dengan modernisme itu itu sendiri. Sejarah panjang modernisme menuntut pemikiran yang kritis dalam melihat kondisi sosial yang terdampak secara langsung dari modernisme itu sendiri. Negara-negara Eropa yang merasakan secara langsung sejarah panjang lahirnya modernisme itu sendiri melihat bahwa terdapat kegagalan besar dalam modernisme. Kekritisan berpikir masyarakat Eropa yang melihat adanya kegagalan dalam modernisme ini juga memberi dampak secara luas terutama di Amerika. Kekritisan pemikiran mengenai kondisi soaial ini pada akhirnya mewujud dalam berbgai gerakan yang ada. Gerakan ini beragam bentuknya dari gerakan sosial hingga gerakan dalam seni.

Gerakan dalam seni khususnya dalam seni musik pada akhirnya memunculkan genre baru dalam musik yaitu hip hop. Hip hop sangat mengkritisi keadaan sosial pada waktu itu yang dinilai tidak memberikan ekuilibrium dalam suatu strata sosial. Aliran baru dalam musik hip hop ini mencoba untuk menyuarakan kondisi sosial ini sehingga hip hop pada akhirnya mendobrak berbagai sekat musik maupun sosial yang ada pada masa itu. Kondisi kemapanan sosial dalam masyarakat didobrak sekat-sekatnya serta keindahan dalam musik pun turut serta didobrak. Keklasikan dalam bermusik bukan lagi menjadi suatu acuan, namun kekritisan atas kondisi sosial yang menjadi rujukan baru dalam bermusik.

Semangat itu pula yang melandasi lahirnya Jogja Hip Hop Foundation. Marzuki 'Kill the DJ' sebagai personil JHF dengan tegas menyatakan bahwa JHF lahir atas dasar semangat kekritisan sosial yang terjadi di Indonesia dan secara khusus di Yogyakarta. Kekritisan ini lebih didasarkan pada nilai-nilai yang menjadi acuan perubahan semnagat modern dan tradisional. Kill the DJ lebih lanjut menyatakan meskipun JHF lahir serta mengkritisi kondisi sosial yang terjadi jauh dari amerika namun semngat JHF juga tidak dapat dilepaskan dari semangat hip hop di Amerika.

Yang membedakan JHF dengan group hip hop yang lainnya adalah JHF lebih mendasarkan diri pada semangat tradisi. Hal ini ditandai dengan masuknya unsur-unsur etnis terutama musik tradisi serta kesenian tradisi berupa pertunjukan wayang kulit yang khas Yogyakarta. Kill the DJ lebih lanjut mengatakan bahwa dalang seperti orang yang sedang melakukan hip hop, sebab di dalam wayang yang dilakukan oleh dalang terdapat free style. Seorang dalang lebih bebas dalam melakukan gerakan ataupun suatu percakapan tertentu. Dalam secara bebas sangat menguasai suatu pertunjukan wayang kulit; dan keadaan ini terjadi sebagaimana seorang hip hop. Hip hop sangat bebas dalam mengeksplorasi maupun mengeaborasi suatu karya maupun pertunjukan.

Semangat tradisi yang dibawa JHF selain dalam musik gamelan maupun dalam wayang kulit juga dapat dilihat dalam karya lagunya yang berjudul Jogja Istimewa. Menurut Kill the DJ, lagu ini memang sengaja diciptakan dan dipersembahkan untuk kota Yogyakarta dimana JHF dilahirkan dan personil JHF tinggal di kota Yogyakarta. Dalam lagu Jogja Istimewa sangat kental sekali nuansa tradisinya khususnya tradisi Yogyakarta. Meskipun sangat kental sekali nuansa tradisi, dalam lagu Jogja Istimewa, JHF juga tidak bisa melepaskannya dari insur hip hop yang sesungguhnya.

Menilik latar belakang lahirnya JHF serta karya-karya yang dihasilkannya maka unsur estetis dalam karya musik hip hop khususnya JHF tidak pernah dapat dilepaskan dari unsur estetis yang melandasi musik hip hop pada umumnya. Namun lebih daripada itu sebenarnya unsur estetis dalam hip hop JHF sangat diwarnai secara kental oleh unsur-unsur tradisi khususnya estetika dalam Kebudayaan Jawa. Hal inilah yang menjadi kekhasan estetika dalam Jogja Hip Hop Foundation. Estetika atas dasar unsur etnis musik tradisi Yogyakarta khususnya gamelan serta pertunjukan wayang kulit sangat mewarnai karya estetis yang dihasilkan JHF. Memang secara mendasar estetika JHF masih diwarnai musik hip hop yang terlahir di masa modern, sehingga estetikanya pun tidak bisa dilepaskan dari estetika modern.

\section{Estetika Hybrid Culture dalam Musik Hip- Hop JHF}

Estetika modern merupakan suatu estetika yang dilandasi atas pendulum objektivitas yang 
sangat kuat. Artinya estetika modern ini mempunyai tolok ukur yang dapat dijadikan parameter ataupun acuan dalam setiap karya seni. Objektivitas estetis sangat dianut sedemikian kuatnya sehingga diluar kerangka objektivitas akan dianggap bukan sebagai sesuatu yang bukan estetis. Terdapat suatu pranata dan struktur yang sangat jelas dalam estetika modern, karena pada dasarnya estetika modern sangat dipengaruhi oleh perkembangan ilmu pada masa modern terutama ilmu-ilmu yang berhubungan dengan alam (naturwissenschaften). Kekuatan ilmu alam dalam mendominasi ilmu diluar ilmu alam memaksa ilmu diluar alam mengikuti pola pemikiran dan perkembangan ilmu alam. Demian pula dengan estetika, maka konsep estetis sangat terasa perubahan terutama dalam makna dan wujudnya.

Semenjak Baumgarten merumuskan teori estetika di masa modern, maka secara otomatis konsep seni dan estetika mengalami perubahan yang sangat drastis. Estetika tidak lagi merujuk kepada sesuatu yang berkaitan dengan keindahan semata, namun estetika lebih kepada persoalan persepsi. Kekuatan persepsi inilah yang menjadi landasan bagi pemahaman estetika di era modern ini. Persepsi haruslah dapat menangkap objek sedemikian sehingga objek dapat mempunyai pemahaman dan interpretasi dalam subjek yang mempersepsi. Pemahaman subjek atas suatu objek ini kemudian menjadi suatu tindakan estetis yang mewujud dalam karya estetis. Karya estetis ini kemudian mempunyai parameter tersendiri dalam dunia modern. Hal ini memang tidak dapat dilepaskan dari pengaruh ilmu alam yang menghendaki adanya parameter atas segala sesuatu. Inilah yang disebut dengan struktur estetis dalam estetika modern. Selain struktur estetis yang terdapat dalam estetika modern, sebenarnya dalam estetika modern juga menghendaki suatu pemaknaan yang sebisa mungkin bersifat general. Itulah keadaan estetika modern yang tidak dapat melepaskan diri dari konsep ilmu alam yang mewarnai abad modern.

Berbeda dengan estetika yang diusung oleh JHF, maka estetika modern tidak begitu dominan kecuali hanya unsur estetika modern yang terwarisi dari genre musik hip hop itu sendiri. Pendulum objektivitas dalam estetika modern dikoreksi begitu baik oleh JHF, sehingga objektivitas estetika modern tidak terasa begitu mutlak. JHF berhasil mengkombinasikan unsur objektivitas dalam estetika modern dengan unsur subjektivitas. Hal ini dapat dilihat dari masuknya unsur tradisi terutama tradisi masyarakat Yogyakarta dalam musik hip hopnya. Objektivitas estetis modern hip hop berhasil dipadukan dengan unsur subjektivitas tradisi. Inilah yang disebut relasionalisme estetika dimana keterpaduan antara objektivitas dan subjektivitas berhasil terpadu dengan cukup baik. Salah satu contoh karya hip hop dari JHF yang dapat menerangkan wujud relasionalisme estetika adalah karya yang berjudul Cintaku Sepahit Topi Miring dan Jogja Istimewa.

Keberhasilan JHF bukan saja menciptakan karya-karya lagu hip hop yang berhasil mencampurkan unsur tradisi maupun modern, namun dalam perspektif estetis, JHF juga berhasil memberikan warna baru serta pemahaman yang baru. Estetika bukan saja dimaknai sebagai kemutlakan yang tidak dapat diganggu gugat, namun estetika lebih kepada persoalan persepsi yang dapat diberikan berbagai unsur baru. Unsur baru tersebut tidak akan menghilangkan atau meniadakan unsur yang sudah ada, namun lebih cenderung untuk melengkapi unsur estetis yang sudah ada.

Dalam perspektif yang lebih teoritis, sebenarnya estetika hip hop dalam karya karya JHF lebih mengarah kepada bentuk estetika postmodern, terutama terutama pemikira postmodern dari pemikiran Jean Baudrillard. Baudrillard menyatakan bahwa dalam masyarakat postmodern ditandai dengan impolsi (ledakan ke dalam) alias peleburan segala batas, wilayah dan pembedaan antara budaya tinggi dan budaya rendah, penampilan dan kenyataan, dan segala oposisi biner lainnya yang selama ini dipelihara oleh teori sosial (Sugiharto, 1996:26). Terlihat sekali bahwa berdasar pemikiran Baudrillard tersebut, maka estetika dalam karya hip hop JHF merupakan suatu bentuk estetika impolsi. JHF ingin menampilkan segala parsialitas dalam Kebudayaan Jawa melalui bingkai generalitas estetika musik hip hop. Impolsitas estetis JHF ini pada akhirnya terlihat mengatasi segala bentuk 
sekat yang ada dalam ranah genre hip hop. Hal ini juga semakin menandaskan bahwa hip hop yang dielaborasi oleh JHF mempunyai keunikan tersendiri, maka tidak heran dalam data JHF, pada tahun 2012, JHF diundang ke negara Paman Sam untuk melakukan konser hip hop di sana. Undangan ini sebenarnya lebih kepada bentuk penghargaan akan kreativitas sintesis antara musik modern hip hop yang dikemas dan diangkat dari kesenian yang tradisional.

Keterpaduan musik modern hip hop yang secara estetis lebih menekankan kepada proses meningkatnyadiferensiasibidang-bidangkehidupan beserta fragmentasi sosial dan alienasinya, maka JHF dalam karya yang dihasilkannya secara estetis dapat ditafsirkan sebagai proses de-diferensiasi dan impolsi peleburan segala bidang. Memang dalam penelitian dicoba untuk dianalisis konsep maupun pemaknaan estetis dalam musik hip hop terutama Jogja Hip Hop Foundation yang mempunyai karakter yang berbeda dengan musik hip hop pada umumnya.

\section{Penutup}

Hip hop merupakan jenis musik yang eksistensi dan konsistensinya terus terjaga, bahkan hip hop terus berkembang dalam ranah musikalitas. Hip hop tidak seperti jenis music lainnya, yang terkadang menjaga nilai keasilannya. Hip hop terus berpadu-padan dengan jenis musik lainnya. Pembauran hip hop dengan jenis musik dan budaya lain menjadikan hip hop semakin variatif. Pembauran itu menjadi kekhasan tersendiri pada hip hop itu sendiri. Hal ini sudah terjadi sejak hip hop itu berdiri, tidak terlepas dari kondisional yang ada dalam terbentuknya hip hop. Hip hop dalam perkembangannya mengalami rentetan proses yang panjang.

Semangat itu pula yang melandasi lahirnya Jogja Hip Hop Foundation. Marzuki 'Kill the DJ' sebagai personil JHF dengan tegas menyatakan bahwa JHF lahir atas dasar semangat kekritisan sosial yang terjadi di Indonesia dan secara khusus di Yogyakarta. Kekritisan ini lebih didasarkan pada nilai-nilai yang menjadi acuan perubahan semangat modern dan tradisional. Kill the DJ lebih lanjut menyatakan meskipun JHF lahir serta mengkritisi kondisi sosial yang terjadi jauh dari Amerika namun semangat JHF juga tidak dapat dilepaskan dari semangat hip hop di Amerika. Yang membedakan JHF dengan group hip hop yang lainnya adalah JHF lebih mendasarkan diri pada semangat tradisi. Hal ini ditandai dengan masuknya unsur-unsur etnis terutama musik tradisi serta kesenian tradisi berupa pertunjukan wayang kulit yang khas Yogyakarta.

Menilik latar belakang lahirnya JHF serta karya-karya yang dihasilkannya maka unsur estetis dalam karya musik hip hop khususnya JHF tidak pernah dapat dilepaskan dari unsur estetis yang melandasi musik hip hop pada umumnya. Namun lebih daripada itu sebenarnya unsur estetis dalam hip hop JHF sangat diwarnai secara kental oleh unsur-unsur tradisi khususnya estetika dalam Kebudayaan Jawa. Hal inilah yang menjadi kekhasan estetika dalam Jogja Hip Hop Foundation. Estetika atas dasar unsur etnis musik tradisi Yogyakarta khususnya gamelan serta pertunjukan wayang kulit sangat mewarnai karya estetis yang dihasilkan JHF. Memang secara mendasar estetika JHF masih diwarnai musik hip hop yang terlahir di masa modern, sehingga estetikanyapun tidak bisa dilepaskan dari estetika modern.

\section{Kepustakaan}

Artaud, Antonin,. 1970. Theatre And Its Double, trans. Victor Corti. United Kingdom: Calder $\&$ Boyars Ltd.

Bhaba, Homi. K. 2007. The Location of Culture. Cetakan ke-5. London, New York: Routledge.

Burke, J.P. 2009. Identity Theory, Oxford: Oxford University Press.

Bourdieu, Pierre.1977. Outline of a Theory of Practice. Cambridge: Cambridge University Press.

.1990. The Logic Of Practice, trans by Richard Nice. Stanford: Stanford University Press.

1994. Distinction: a social critique of the judgment of taste. London: Routledge.

Clark, Jude. 2003. Introduction: Urban Culture: 
Representations and Experiences in/of Urban Space and Culture. Agenda, No. 57, Urban Culture (2003), pp. 3-10.

Goldberg, Roselee,. 1988. Performance Art from Futurism to the Present. London: Thames \& Hudson.

Huxley, Michael \& Noel Witts. 1968. The Twentieth-Century Performance Reader. London: Routledge.

Hauser, Arnold. 1982. The Sociology of Art, terj. Kenneth J. Northcott. London: University of Chicago Press.

Jamieson, Alison (ed.). 2007. Antonin Artaud:

From Theory to Practice. London: Greenwich Exchange.

Jenkins, Richard. 1990. Dimensions of Adulthood in Britain: Long term Unemployment and mental handicap, in P. Spencer (ed.) Anthropology and the Dirddle of The Sphinx: Paradoxes of Change in the Life Course, London: Routledge. 1992. Pierre Bourdieu "Key Sociologists". London: Routledge. 2013. Membaca pikiran Pierre

Bourdieu, terj., Nurhadi. Bantuk: Kreasi wacana

Kayam, Umar. 1981. Seni, Tradisi dan Masyarakat. Jakarta: Sinar Harapan.

Koentjaraningrat, 1994. Kebudayaan Jawa. Jakarta: Balai Pustaka.

Lockard, Craig A. 1998. Dance Of Life, Popular
Music and Pokitics in Southeast Asia. Honolulu: University of Hawai'I Press.

Lynch, Gordon. 2005. Understanding Theology and Popular Culture. Victoria: Blackwell

Poerwadarminta, W.J.S. 1939. BAOESASTRA $D J A W A$. Batavia: J.B. Walter Uitgevers Maatschappij n.v. Groningen.

Richter, Max M. 2012. Musical Worlds in Yogyakarta. Leiden: KITLV Press.

SeloSumardjan. 1980. "KeseniandalamPerubahanK ebudayaan"dalamAnalisisKebudayaantahun 1 no.2. (1980/1981)

Shuker, Roy. 1994. Understanding Popular Music. New York: Routledge.

Spreadley, James P. 2007. Metode Etnografi. Terj Misbah Zulfa Elizabeth, Yogyakarta: PT. Tiara Wacana.

Sumardjo, Jakob. 2010. Estetika Paradoks. Bandung: Sunan Ambu Press.

Turner, K. 1984.Mass Media and Popular Culture, Chicago: Science Research Association

Usman, Sunyoto. 2000. "Apresiasi Masyarakat Terhadap Musik Populer" dalam Ketika Orang Jawa Nyeni, Ahimsa-Putra (ed). Yogyakarta: Galang Press.

Weirtheim, W.F.1964. Indonesian Society In Trasition. A Study of Social Change. The Hague: W. ban Hoewe; Bandung: Sumur Bandung.

Young, Robert J.C. 1995. Hybridity in Theory, Culture and Race. London, Routledge 